\title{
CAMPYLOBACTER SPP.: \\ VALUTAZIONE DI UN SISTEMA AUTOMATICO DI ISOLAMENTO.
}

\author{
Pescetto L., Ricagni L., Ferrari P, Valente V., Galeazzi G., \\ Formiga A., Bandettini R. \\ Laboratorio Analisi Chimico-Cliniche e Microbiologia \\ Istituto Giannina Gaslini, GENOVA.
}

Introduzione: Campylobacter jejuni e Campylobacter coli sono i principali responsabili di enteriti umane.

Lo scopo del nostro lavoro è stato quello di valutare un sistema automatico per l'isolamento di Campylobacter spp. confrontandolo con la tecnica tradizionale utilizzata nel nostro laboratorio.

Materiali e metodi:

Abbiamo testato 105 campioni di feci per Campylobacter utilizzando un sistema automatico (Robobact - Diesse). L'isolamento avviene nel Coprobact Campylobacter, costituito da un doppio slide le cui due superfici sono ricoperte da due terreni selettivi per Campylobacter, rispettivamente il $\mathrm{CAB}$ (addizionato a sangue di montone) e il CCDA (contenente carbone).

La semina avviene in automatico dopo arricchimento in Coproset Campylobacter, contenente il Campylobacter Selective Broth. Segue l'incubazione a $42^{\circ} \mathrm{C}$ per 48 ore in microaerofilia. Gli stessi campioni sono stati testati con lo stesso metodo dopo refrigerazione per 24 ore a $2-8^{\circ} \mathrm{C}$ in Coproset. Come riferimento abbiamo eseguito la semina su un terreno selettivo al sangue addizionato a 5 antibiotici (Campylobacter agar - Becton Dickinson) ed incubati a $42^{\circ} \mathrm{C}$ per 48 ore in microaerofilia (Campy Pouch Microaerophilic System - Becton Dickinson). Abbiamo inoltre valutato con entrambe le metodiche un ceppo ATCC 33291 Campylobacter jejuni.

\section{Risultati e Discussione:}

Dei 105 campioni processati 6 sono risultati positivi per Campylobacter spp. sia in automatico (inoculazione diretta in coproset e dopo refrigerazione) che in manuale. In 1 campione $(16,7 \%)$, dopo refrigerazione si ha avuto crescita solo sul $\mathrm{CAB}$ probabilmente per una maggiore selettività di questo terreno e/o una bassa carica vitale dell'isolato. La buona performance del metodo associato alle caratteristiche tecniche quali la possibilità di conservare il campione per 24 ore a $2-8^{\circ} \mathrm{C}$ senza compromettere le possibilità di isolare il Campylobacter costituisce un'ottima alternativa al metodo manuale soprattutto per strutture con grande routine. 